\title{
High Density NOAA Time Series of ET in the Gediz Basin, Turkey
}

\author{
Ambro Gieske, Wouter Meijninger ${ }^{1}$
}

\begin{abstract}
An evapotranspiration method comparison study was carried out by the International Water Management Institute (IWMI, Sri Lanka), at two locations in the Gediz Basin, Turkey, in the period from May until September 1998. A number of ground-based techniques were compared with results obtained by remote sensing methods. Recently, a search of the Satellite Active Archive yielded over 70 high quality level $1 \mathrm{~b}$ images of the same time period. The processing of these images with the SEBAL algorithm enabled us to build up a detailed time series of sensible and latent heat fluxes for a period of 120 days. In this study a comparison is made between the sensible and latent heat fluxes determined from the present series of NOAA-14/AVHRR images and the results obtained earlier in the 1998 IWMI project.
\end{abstract}

\section{Introduction}

The International Water Management Institute (IWMI) brought researchers together in the Gediz Basin, Turkey, in 1998 to carry out a comparison between eight different methods to evaluate actual evapotranspiration. These included both field and remote sensing methods. The results and conclusions of this study were published in a special issue of the Journal of Hydrology (Kite and Droogers, 2000). While testing some technical issues relating to both remote sensing (Gieske, 2003) and field (scintillometer) methods (Meijninger, 2003), it was realized that further validation was possible through use of the NOAA/AVHRR level $1 \mathrm{~b}$ (LAC) images stored in the Satellite Active Archive (www/saa.noaa.org).

\footnotetext{
${ }^{1}$ ITC, International Institute for Geo-Information Science and Earth Observation, Water Resources Division, P.O. Box 6, 7500 AA Enschede, The Netherlands; Wageningen University, Meteorology and Air Quality Group, Duivendaal 2, 6701 AP Wageningen, The Netherlands.
} 
Nowadays remote sensing algorithms for estimating the regional surface fluxes (e.g. evaporation) are widely used. Most of these were developed in the last decade (see e.g. Kustas et al., 1996, Bastiaanssen et al., 1998, Timmermans et al., 2003) and can be applied to imagery of satellites, such as Landsat and AVHRR. For MODIS images evapotranspiration (Nishida et al., 2003) will even be offered as a standard product in the near future. The main advantage of a remote sensing technique is that it can provide regional estimates of the surface energy balance terms, while most conventional techniques are point measurements that are representatives of small areas (i.e. source area). Although high-resolution satellites such as LANDSAT (30m) and ASTER (15m) are preferable for detailed studies, coarse resolution imagers such as NOAA/AVHRR (1 km at nadir) and MODIS (250-1000m) have the advantage of almost daily scene coverage and are essentially freely obtainable from the Satellite Image Archives. Therefore these are well suited for agroclimatological monitoring.

Recently, validation studies of remote sensing algorithms have been conducted using ground based scintillometer data (Bastiaanssen, 2000; Hemakumara et al., 2002; Lagouarde et al., 2003; Roerink et al., 2000; Watts et al., 2000, Meijninger, 2003). The scintillation method can estimate the sensible heat flux from the propagation statistics of an electromagnetic wave emitted over a certain distance along the surface (see e.g. De Bruin et al., 1995). The advantage of the method is that it can provide surface fluxes of sensible heat at scales comparable to remote sensing methods. For example, Kohsiek et al. (2002) have demonstrated that the scintillation method can be applied over distances up to 10 kilometres. As a result the difference in observational scale between the remote sensing method and the ground observations decreases.

In this study a remote sensing algorithm known as SEBAL (Surface Energy BALance) (Bastiaanssen et al., 1998) is applied to NOAA-14 AVHRR level 1b (LAC) data, which have been downloaded from the Satellite Active Archive (SAA). The algorithm computes most essential hydro-meteorological parameters empirically and requires only little field information (incoming solar radiation, air temperature and wind speed data). The sensible heat flux $\mathrm{H}$ is solved iteratively using Monin-Obukhov Similarity Theory (MOST) and the latent heat flux LE is derived as the closure term of the surface energy balance equation.

$$
L E=\left(R_{n}-G\right)-H
$$


The purpose of this study is to compare the SEBAL derived sensible heat fluxes with other techniques such as ground based scintillometer and in-situ (variance method) surface fluxes from two different sites for a period spanning a growing season (118 days). We have used data from an experiment that took place in the Gediz river basin (Turkey) in 1998 (Kite and Droogers, 2000, Meijninger and de Bruin, 2000). In Section 2 all three methods are explained and the experimental set-up is described in Section 3. In Section 4 the results are presented and discussed while finally, in Section 5 the conclusions are given.

\section{Materials and methods}

1. NOAA-14 image processing and atmospheric corrections

The level 1b NOAA-14 AVHRR data were downloaded from the Satellite Active Archive (www.saa.noaa.gov). Images where the study site was too far from nadir (extreme viewing angles) or too cloudy were discarded, resulting in 73 images between day number (DOY) 152 and 277. The images were first resampled to a latitude-longitude grid with a pixel size of 0.01 degree, basically according to the method by Di and Rundquist (1994). However, the quality of the resampling was much improved through the use of a two-dimensional filter technique rather than the crude one-dimensional row filter proposed by the latter authors. Geocorrection to within one pixel accuracy was done through the use of DCW segment maps of the Turkey coastline.

Pre-processing of AVHRR channels 1 and 2 consisted of the conversion of raw counts to \% reflectance values with post-launch NOAA-14 calibration (Rao and Chen, 1996). The thermal channels 4 and 5 were calibrated into radiances and then into brightness temperatures by inverting the Planck function. All steps described above are implemented in a small computer program (NPR1b), which is available from the author on request.

For the narrow-band to broad conversion using channel 1 and 2 the empirical constants

proposed by Valiente et al. (1995) were applied. Finally, the method of Gutman (1988) was used to derive monthly mean surface albedo values in order to correct for the fluctuations in the surface reflectance due to angular variability of the AVHRR sensor and bi-directional effects. 


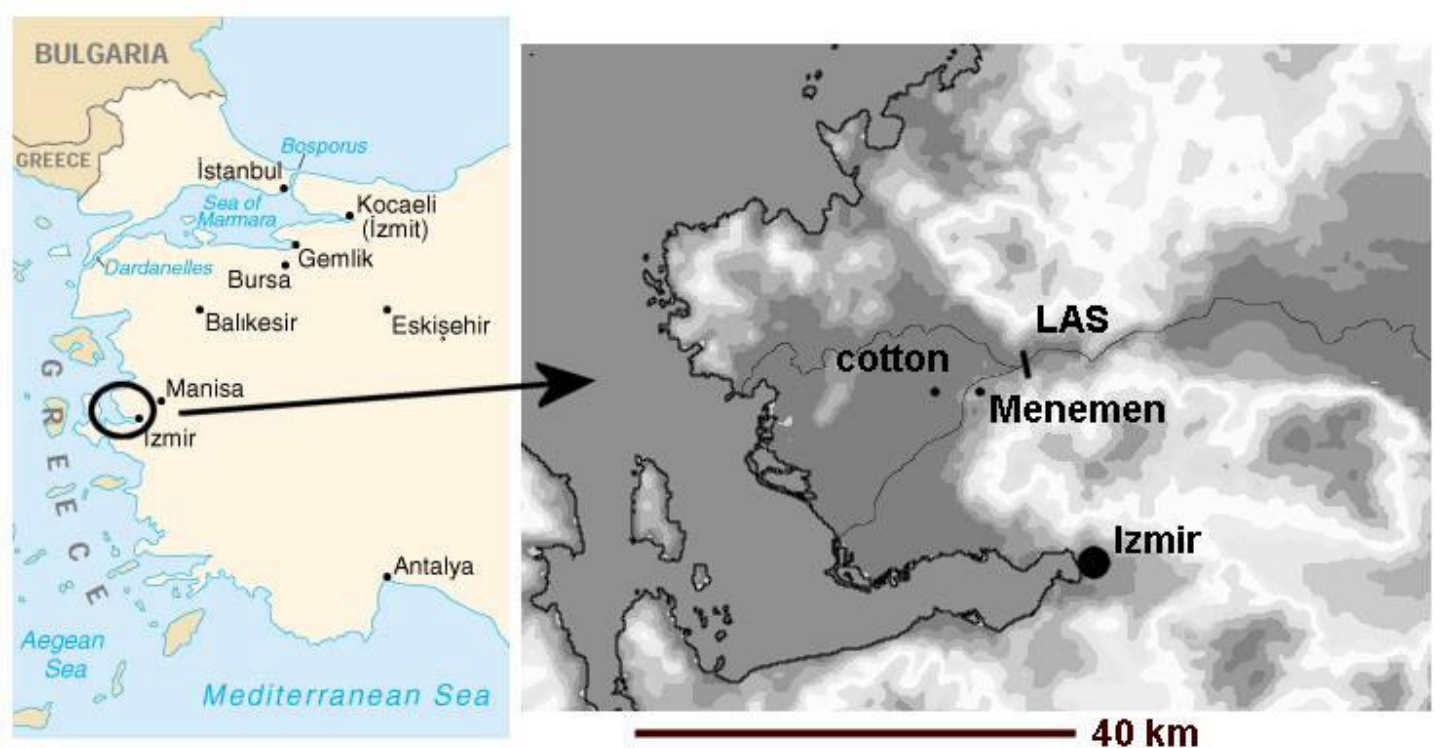

Fig. 1: Map of western part of Turkey (left) showing the locations of the cotton field, the LAS set-up in the valley and the Menemen climate station (right).

2. The scintillation and temperature variance methods

The scintillation method is based on the analysis of intensity fluctuations (known as scintillations), of a near-infrared light beam $(\lambda=0.94 \mu \mathrm{m})$ that has propagated over a horizontal distance $(L)$ between the transmitter and the receiver (see Figs. 2 and 3) In this case a large aperture scintillometer (LAS) is used with an aperture diameter $(D)$ of $0.15 \mathrm{~m}$, which makes it possible to measure over distances up to $5 \mathrm{~km}$.

The observed light intensity fluctuations are related to fluctuations of the refractive index of air, which in turn are related to temperature variations (De Bruin et al., 1995, Meijninger, 2003). These can then be related to the sensible heat flux H, which is derived iteratively by applying the Monin-Obukhov Similarity Theory (MOST). In addition the Bowen ratio appears in the equations, and this parameter needs to be determined with standard meteorological equipment. For stable conditions the validity of the scintillation method is uncertain. Because the fluxes are usually small the nighttime flux is set at $0 \mathrm{~W} \mathrm{~m}^{-2}$ for estimating the daily average sensible heat flux $\left(H_{24}\right)$. 


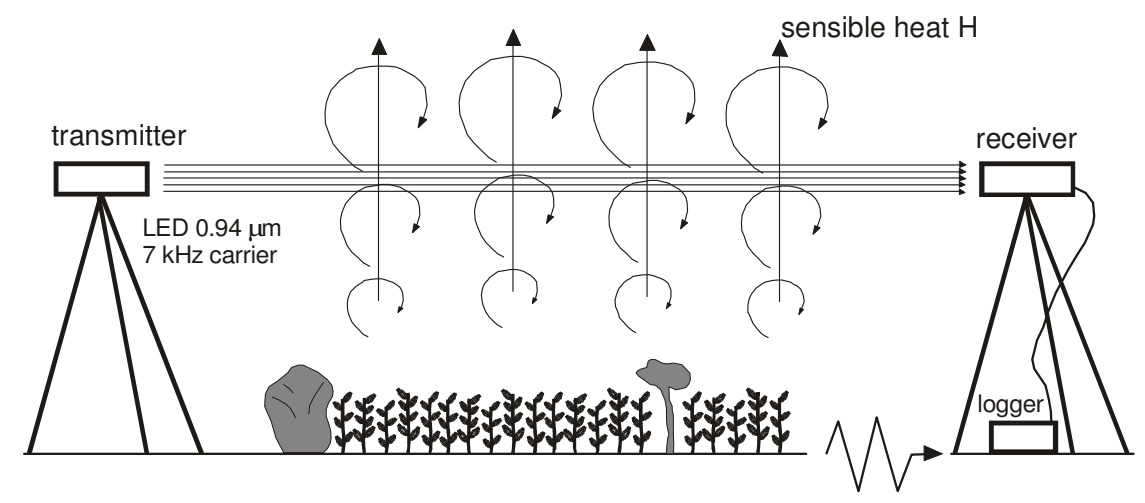

Fig. 2. The figure shows the operational principle of a scintillometer. Light from a Light Emitting Diode (LED, $0.94 \mu \mathrm{m}$ ) is bundled into a parallel beam and modulated by a $7 \mathrm{kHz}$ oscillator. At distances of $200 \mathrm{~m}$ to several $\mathrm{kms}$ the light signal is amplified by a receiver to produce a signal that is representative of changes in the refractive index of the atmosphere. These in turn are caused by the flow of sensible heat from the surface into the atmosphere. The set-up shown here makes use of $3 \mathrm{~m}$ high tripods. In practice high towers or hills are often required to measure over undulating terrain and tall trees.

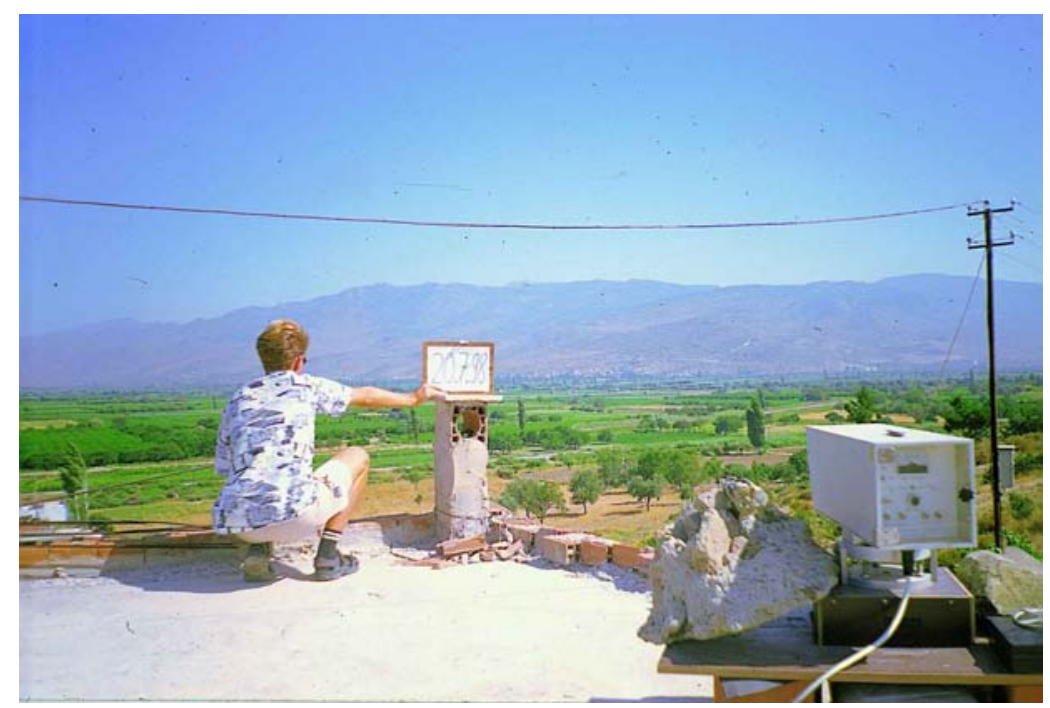

Fig. 3. The figure shows the LAS receiver. The transmitter is on the hill slope across the valley.

The temperature variance method, a conventional 'point' method, is also based on MOST and can estimate the sensible heat flux from temperature fluctuation measurements $\left(\sigma_{T}\right)$ collected by a fast response thermocouple (Tillman, 1972).

In this case on site wind speed data is used to estimate the friction velocity. As is the case with the scintillation method, the validity of the variance method during stable conditions is 
uncertain. Therefore we followed the same procedure to derive the daily average sensible heat flux and set the sensible heat flux during the night also equal to zero.

\section{Energy balance calculations with SEBAL}

In this study the program SHEBA (Delphi Pascal) is used. This program implements the main characteristics of the SEBAL method (Surface Energy BALance, see Bastiaanssen et al, 1998; Bastiaanssen, 2000) but it is specifically designed to be more efficient and faster $(\approx 5 \times)$ in calculating the sensible heat fluxes (Gieske, 2003). Throughout this paper we will refer to SEBAL to indicate the remote sensing method. The algorithm consists of a number of steps to solve the energy balance for each pixel. Here it is applied to surface albedo, brightness temperature and NDVI (Normalised Difference Vegetation Index) maps based on NOAA-14 AVHRR data (channels 1, 2, 4 and 5). The instantaneous net radiation $\left(R_{n}\right)$ is computed from incoming and reflected solar and thermal radiation, where the incoming short wave radiation is taken from the Menemen climate station. The outgoing long wave radiation is computed from the radiometric surface temperature. The incoming long wave radiation is derived from the air temperature taken from the Menemen climate station and the effective atmospheric emissivity, which in turn is derived from the atmospheric transmittance. The instantaneous soil heat flux $\left(G_{s}\right)$ is determined according to the empirical relationship proposed by Bastiaanssen et al. (1998). The sensible heat flux for each pixel $\left(H_{x}\right)$ is derived from flux inversion at a selected dry pixel (where $\left.H_{d r y}=\left(R_{n}-G_{s}\right)_{d r y}\right)$ and a wet pixel (where $H_{\text {wet }}=0 \mathrm{~W} \mathrm{~m}^{-2}$ ) inside the image.

The extreme pixels within the image were carefully selected in the Aegean Sea (wet pixel) and north of the city Izmir (dry pixel). The sensible heat flux is solved iteratively applying MOST and using wind speed data that was extrapolated to the blending height and assumed to be constant for the entire image. Finally, the latent heat flux $(L E)$ may be computed as the residual of the surface energy balance equation (Eq. 1). However, in order to facilitate comparison with the sensible heat flux, use is made of the instantaneous evaporative fraction $\Lambda$, defined as follows

$$
\Lambda=\frac{\left(R_{n}-G\right)-H}{R_{n}-G}
$$


Assuming that the evaporative fraction $(\Lambda)$ is constant over the day the daily average sensible heat $\left(H_{24}\right)$ can be derived from $\Lambda$ and the daily average net radiation $\left(R_{n 24}\right)$ as follows

$$
H_{24}=(1-\Lambda) R_{n 24} .
$$

Note that it is also possible to compare the instantaneous sensible heat values $\mathrm{H}_{\mathrm{LAS}}$ and

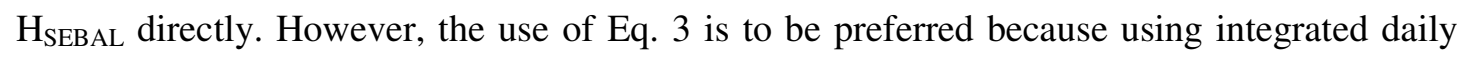
values smoothes the intrinsic fluctuations in $\mathrm{H}_{\text {LAS. }}$. Furthermore, errors in the determination of $H_{\text {SEBAL }}$ due to errors in the term $R_{n}-G$, are also partly compensated by the use of $\Lambda$ as in Eq. 2 .

\section{Study Site and experimental design}

The LAS was deployed across a valley located in the Gediz river basin (Figs 1,2 and 3) east of Menemen (western part of Turkey). The path length of the LAS was $2.7 \mathrm{~km}$ and the effective height of instrument over the valley was $18 \mathrm{~m}$. The land use in the valley consisted of raisin grape $(60 \%)$, cotton $(15 \%)$, fruit trees $(15 \%)$, pasture $(5 \%)$ and other trees $(5 \%)$ (Kite and Droogers, 2000). Other measurements were conducted over an irrigated cotton field located west of Menemen (the distance between both locations is approximately $11 \mathrm{~km}$ ), which is surrounded by other cotton fields. A small mast with a cup anemometer and a fast thermocouple provided statistics of wind speed and temperature at a height of $3 \mathrm{~m}$. Also a net radiometer and a soil heat flux plate were installed to measure net radiation and soil heat flux. Additional meteorological data (hourly values of temperature, wind speed and global radiation) were taken from the Meteorological station in Menemen. In Figure 1 the locations (cotton field, Menemen climate station, LAS) are shown. More detailed information on the experiment can be found in Meijninger and De Bruin (2000).

\section{Results and discussion}

The daily average net radiation from SEBAL is compared with the ground observations in Fig. 4. The plotted SEBAL net radiation is the average of 4 neighbouring pixels, and spatial variation is below $10 \mathrm{Wm}^{-2}$. In Fig. 4 the regression analysis yields $R_{n 24}$ _cotton $=0.95 R_{n 24}$ SEBAL with a RMSD of $20 \mathrm{~W} \mathrm{~m}^{-2}$, equal to $12 \%$. A similar analysis was made for the instantaneous 
measurements (Meijninger, 2003). However, for reasons of space these are not further discussed here. Most of the scatter in the $\mathrm{R}_{\mathrm{n} 24 \text { _cotton }}$ appears to be caused by flood-irrigation (see also Fig. 5). On days of irrigation and following days $(\sim 4)$ the ground measurements show a distinctive increase in the net radiation, which is a combined effect of a decrease in the surface albedo and the surface temperature. The raw AVHRR data did not clearly reveal the effects of irrigation because most variation seems to be caused by changes in sun and satellite viewing angles.

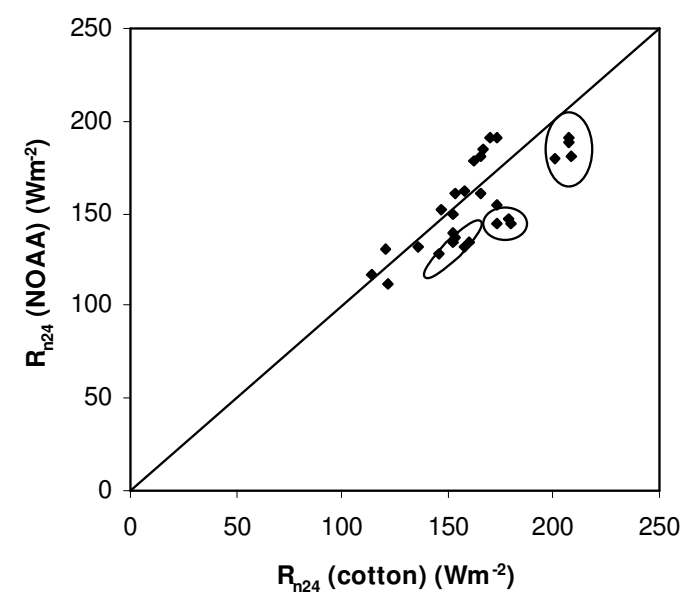

Figure 4: Daily average values of $R_{n 24}$, where SEBAL values are compared with those determined with the weather station on the cotton field. The data points within the circle represent days when the field was flood irrigated.

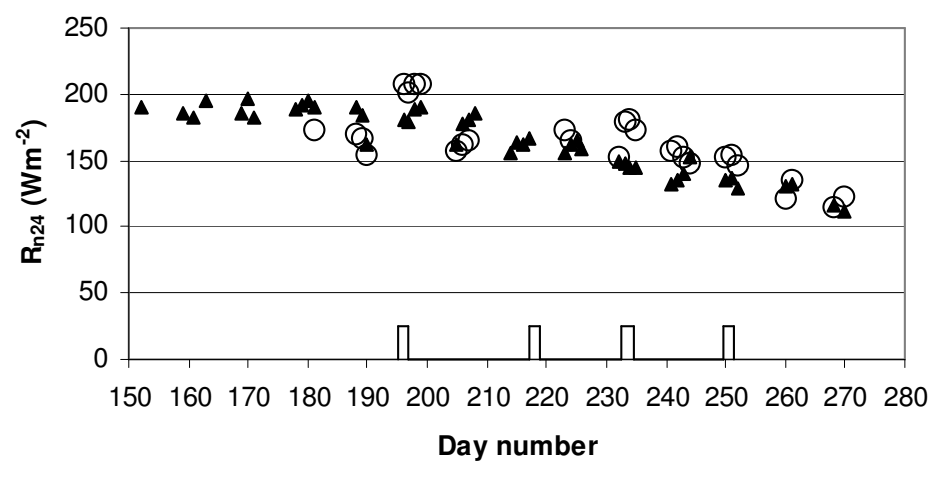

$\triangle$ NOAA image derived $O$ weather station derived _ irrigation

Fig. 5. Daily values of $R_{n 24}$ plotted against day number. NOAA/SEBAL values are compared with those determined with the weather station on the cotton field. The rectangles indicate the days when the fields were flood-irrigated. 


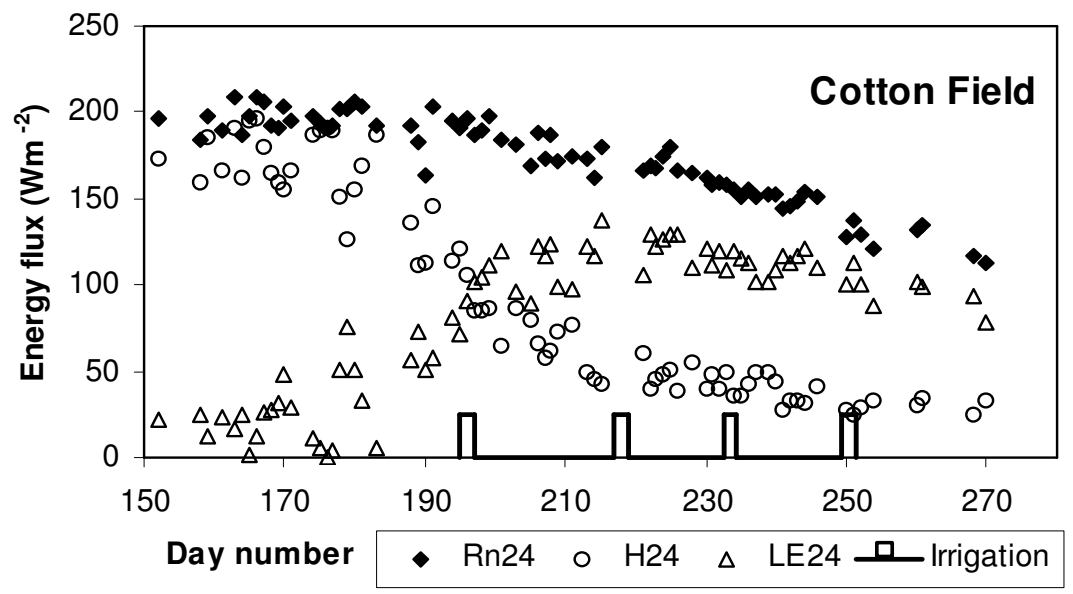

Fig. 6. Daily values of net radiation, sensible and latent heat fluxes, derived from the NOAA/SEBAL analysis, plotted against day number. The evapotranspiration increases sharply at the beginning of the flood irrigation, whereas the sensible heat flux decreases.

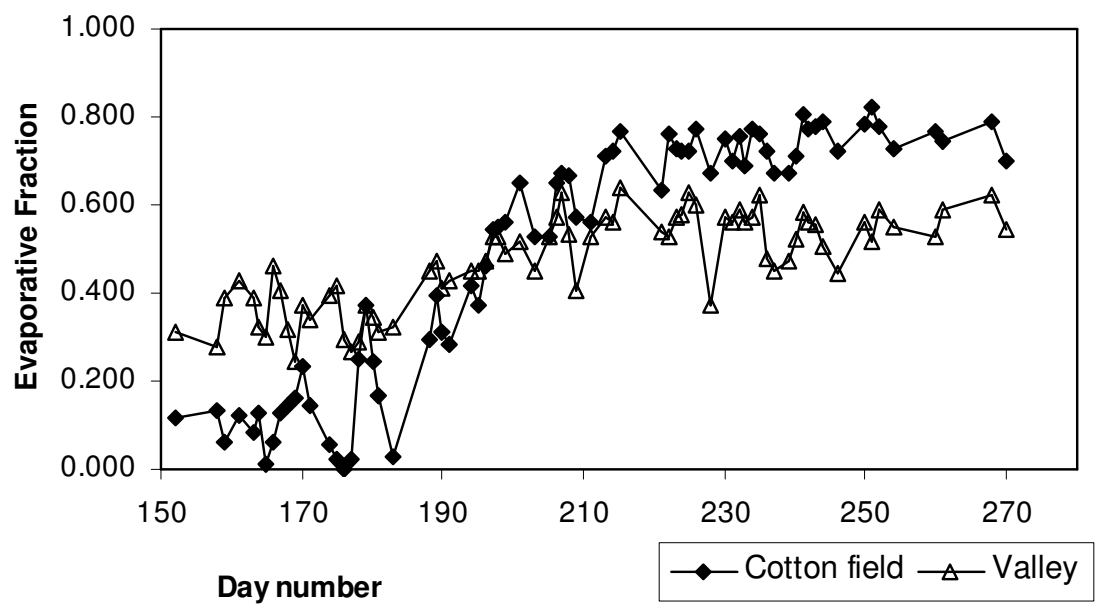

Fig. 7. The figure shows the change in evaporative fraction $\Lambda$ for both the homogeneous cotton area and the more heterogeneous valley area.

Daily values of net radiation, sensible and latent heat fluxes, derived from the NOAA/SEBAL analysis, are plotted against day number in Fig. 6. The figure shows how evapotranspiration increases sharply at the start of the flood irrigation, whereas the sensible heat flux decreases. The NOAA/SEBAL results shown in the figure are averages of 6 neighbouring pixels where the spatial variation of the surface flux was generally less than $30 \mathrm{Wm}^{-2}$. Meijninger et al. (2003) suggest on the basis of the temperature variance method that the sensible heat flux may be overestimated by the NOAA/SEBAL procedures in the initial (non-irrigated) period. 
Fig. 7 shows the difference in evaporative fraction evolution between the irrigated cotton field area and the more heterogeneous valley area covered with trees, pasture and cultivated fields. It should be noted that the valley is only about $2 \mathrm{~km}$ wide at the location of the LAS instrument. Hence there are at best only two pixels, which can be compared to the situation in the valley floor. Often pixels represent both valley and hill slope areas. Moreover, maximum resolution only occurs when the study area is in the nadir position of the NOAA images. Away from this the resolution decreases from $1 \mathrm{~km}$ to $4 \mathrm{~km}$ near the edges.

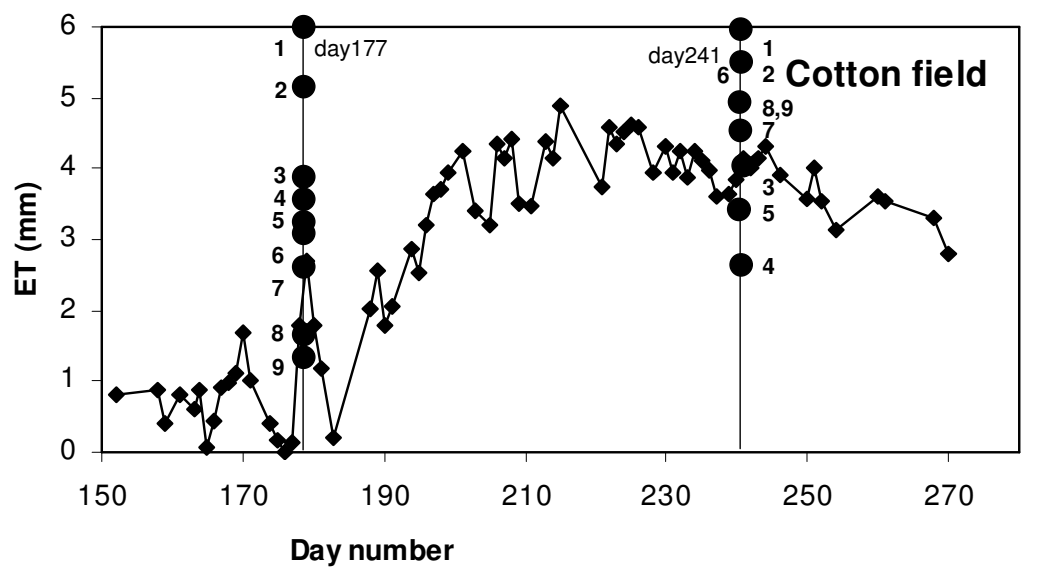

Fig. 8. The evapotranspiration sequence according to the NOAA/SEBAL processing in the cotton field area. For comparison the values reported by Kite and Droogers (2000) have been indicated as follows:

(1) biophysical (2) FAO-24 (3) variance (4) Feedback NOAA (5) Feedback Landsat (6) FAO-56 (7) SEBAL Landsat (8) SWAP (9) SLURP.

Figure 8 shows the evapotranspiration sequence according to the NOAA/SEBAL processing in the cotton field area. The values reported by Kite and Droogers (2000) have been indicated for comparison as follows: (1) biophysical (2) FAO-24 (3) variance (4) Feedback NOAA (5) Feedback Landsat (6) FAO-56 (7) SEBAL Landsat (8) SWAP (9) SLURP. More details on these methods may be found in special issue 229 of the Journal of Hydrology. The figure indicates the enormous range of reported results. Remarkably, the results agree most with methods (8) and (9). Clear outliers are methods (1), (2) and (4). One should note that an evapotranspiration of $6 \mathrm{~mm}$ corresponds to an energy flux of $170 \mathrm{Wm}-2$, which is very near the maximum available energy according to Figs. 5 and 6. 


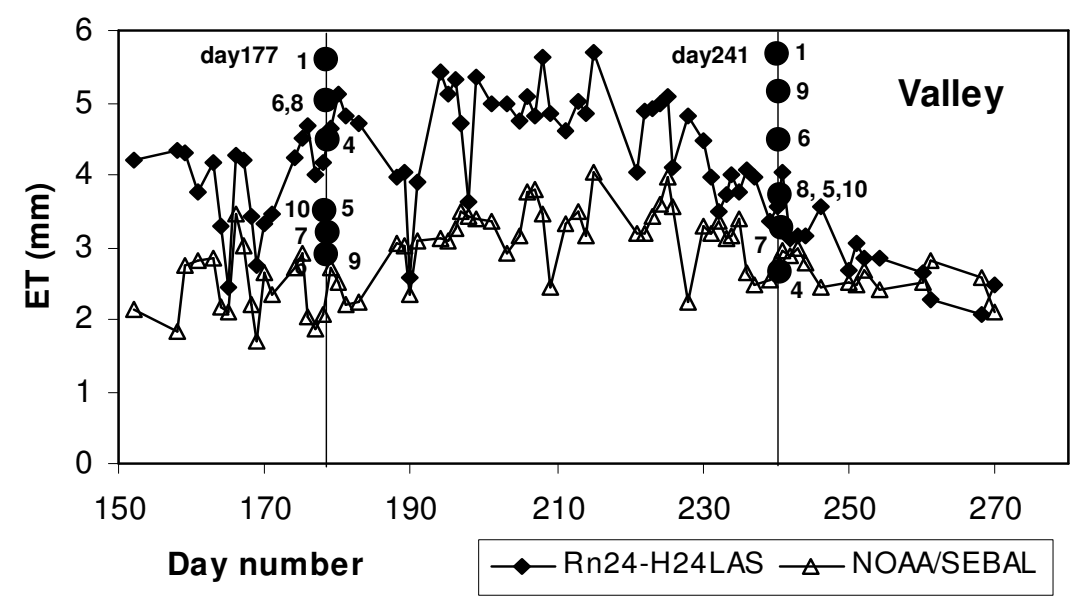

Fig. 9. The evapotranspiration sequence according to the NOAA/SEBAL and HLAS processing in the valley area. For comparison the values reported by Kite and Droogers (2000) have been indicated as follows: (1) biophysical (4) Feedback NOAA (5) Feedback Landsat (6) FAO-56 (7) SEBAL Landsat (8) SWAP (9) SLURP (10) LAS scintillometer.

Figure 9 shows the development of the evapotranspiration in the valley according to the NOAA/SEBAL processing and according to the scintillometer results. Use is made of the NOAA derived daily net radiation $R_{n 24}$ received by the valley surface. It was found that $R_{n 24}$ data correspond very well with the data of the cotton field area, which in turn highly correlate with the weather station data at that location (Figs. 4, 5, 6). Therefore we could put $\mathrm{ET}_{\mathrm{LAS}}=\mathrm{R}_{\mathrm{n} 24}-\mathrm{H}_{24 \mathrm{LAS}}$, whereas $\mathrm{ET}_{\mathrm{NOAA}}$ was obtained as $\Lambda \mathrm{R}_{\mathrm{n} 24}$. For comparison the values reported by Kite and Droogers (2000) have also been indicated in the figure. One explanation for the difference between $\mathrm{ET}_{\mathrm{LAS}}$ and $\mathrm{ET}_{\mathrm{NOAA}}$ may perhaps be the following: $\mathrm{ET}_{\mathrm{NOAA}}$ is derived using the instantaneous evaporative fraction $\Lambda$, which is assumed to remain constant during the day. During days of near-ideal conditions (no clouds, clear sky, calm conditions) this appears to be a fair assumption (see also the discussion in Meijninger, 2003). The ET $_{\text {LAS }}$ on the other hand is determined through the use of integrated values of instantaneous $\mathrm{H}_{\mathrm{LAS}}$ observations, where conditions are normally not ideal. Therefore $\mathrm{H}_{24 \mathrm{LAS}}$ is normally lower than what one would expect under "ideal" conditions and then $\mathrm{ET}_{\mathrm{LAS}}$ is higher. Conversely when conditions are ideal, one would expect the methods to agree. Inspection of the two graphs in Fig. 9 shows that this might be the case for a couple of isolated days in the initial 
period, and more consistently towards the end of the study period. The LAS results would then correspond more to actual field conditions, whereas the NOAA/SEBAL results would reflect the evapotranspiration that would occur if the evaporative fraction remained constant during the day. One should note as mentioned before, that the small size valley conditions are not well suited for NOAA modelling. Apart from the pixel composition and size problem, there may also be micrometeorological complications due to, for example, air circulation through the valley, that would violate the SEBAL assumptions.

\section{Conclusions}

In this study surface flux maps of sensible heat generated by a satellite remote sensing technique (NOAA/SEBAL) have been compared with ground observations. The ground measurements were conducted at two different locations, in a homogeneous cotton field area and in a more heterogeneous valley, about $2 \mathrm{~km}$ wide. The daily net radiation values obtained through the NOAA/SEBAL modelling are in good agreement with those observed in the cotton field area. The instantaneous latent and sensible heat fluxes provided by NOAA/SEBAL correspond well with the ground measurements for the cotton site over the entire growing season. However, Meijninger (2003) noted that daily fluxes obtained from the temperature variance method deviated somewhat from those obtained by the NOAA/SEBAL series for the first part of the period. For the valley site, where the LAS was installed, the results show a larger discrepancy. The spatial coverage of the LAS (i.e. source area) in the heterogeneous valley may have been too small compared to the spatial resolution of the AVHRR images. Furthermore, we suspect that the valley is too narrow for the AVHRR's spatial resolution, leading to pixels of mixed composition. However, a possible explanation may be that the $\mathrm{ET}_{\mathrm{LAS}}$ calculation is based on integrated measurements of the sensible heat flux during the day, whereas the SEBAL methods operates on the assumption of a constant evaporative fraction. Under "ideal" conditions the results of the two methods would converge. Another problem (Meijninger, 2003) could perhaps be caused by difficulties in identifying dry pixels in the area, especially in the first part of the study period, leading to overestimation of the sensible heat flux. Work is underway to validate satellite remote sensing techniques using longer scintillometer path lengths up to $10 \mathrm{~km}$ using the XLAS (Kohsiek et al., 2002), which allows a better comparison with the low-resolution satellites (NOAA/AVHRR, METEOSAT MSG). Furthermore, a satellite-scintillation combination will be investigated where relative 
extreme 'scintillometer' pixels will be used to apply SEBAL to areas where wet and dry pixels are not present. Notwithstanding these difficulties, however, the present study has shown that highly detailed time series of evapotranspiration are possible with the present state of NOAA/AVHRR archives and techniques.

\section{References}

Bastiaanssen, W. G. M., Menenti, M., Feddes, R. A. and A.A.M. Holtslag, A. A. M. 1998, A Remote Sensing Surface Energy Balance Algorithm for Land (SEBAL) - 1. Formulation, Journal of Hydrology 212-213: 198-212.

Bastiaanssen, W. G. M. 2000. SEBAL-Based Sensible and Latent Heat Fluxes in the Irrigated Gediz Basin, Turkey. Journal of Hydrology 229: 87-100.

De Bruin, H. A. R., Van den Hurk, B. J. J. M., and W. Kohsiek. 1995. The Scintillation Method Tested Over a Dry Vineyard Area. Boundary-Layer Meteorology 76: 25-40.

Di, L. and D.C. Rundquist. 1994. A One-Step Algorithm for Correction and Calibration of AVHRR Level 1b Data. Photogrammetric Engineering and Remote Sensing 60(2): 165-171.

Gieske, A. 2003. The Iterative Flux-Profile Method for Remote Sensing Applications. International Journal of Remote Sensing 24(16): 3291-3310.

Gutman, G. 1988. A Simple Method for Estimating Monthly Mean Albedo of Land Surfaces from AVHRR Data. Journal of Applied Meteorology 27: 973-988.

Hemakumara, H. M., Chandrapala, L. and A. F. Moene. 2003. Evapotranspiration fluxes over mixed vegetation areas measured from large aperture scintillometer. Agricultural Water Management 58: 109-122.

Kite, G. W. and P. Droogers. 2000. Comparing Evapotranspiration Estimates from Satellites, Hydrological Models and Field Data. Journal of Hydrology 229: 3-18. 
Kohsiek, W., Meijninger, W. M. L., Moene, A. F., Heusinkveld, B. G., Hartogensis, O. K., Hillen, W. C. A. M. and H.A.R. De Bruin. 2002. An Extra Large Aperture Scintillometer (XLAS) with a 9.8 km Path Length. Boundary-Layer Meteorology 105: 119-127.

Kustas, W.P., Humes, K.S., Norman, J.M. and M.S. Moran. 1996. Single- and Dual-Source Modelling of Surface Energy Fluxes with Radiometric Surface Temperature. Journal of Applied Meteorology 35: 110-121.

Lagouarde, J. -P., Jacob, F., Gu, X. -F., Olioso, A., Bonnefond, J. -M., Kerr, Y., McAneny, K. and M. Irvine. 2002. Spatialization of Sensible Heat Flux over a Heterogeneous Landscape. Agronomie 22: 627-633.

Meijninger, W. M. L. and H.A.R. De Bruin. 2000. The Sensible Heat Fluxes over Irrigated Areas in Western Turkey Determined with a Large Aperture Scintillometer. Journal of Hydrology 229: 42-49.

Meijninger, W.M.L. 2003. Surface Fluxes over Natural Landscapes using Scintillometry. PhD Dissertation, Wageningen University, The Netherlands, pp 164.

Nishida, K., Nemani, R. R., Running, S. W. and J.M. Glassy. 2003. An operational remote sensing algorithm of land surface evaporation. Journal of Geophysical Research 108(D9): 4270.

Rao, C.R.N., and J. Chen. 1996. Post-Launch Calibration of the Visible and Near-Infrared Channels of the Advanced Very High Resolution Radiometer on the NOAA-14 Spacecraft. International Journal of Remote Sensing 17: 2743-2747.

Roerink, G. J., Su, Z. and M. Menenti. 2000. S-SEBI: A Simple Remote Sensing Algorithm to Estimate the Surface Energy Balance. Physics and Chemistry of the Earth 25: 147-157.

Tillman, J. E. 1972. The indirect Determination of Stability, Heat, and Momentum Fluxes in the Atmospheric Boundary Layer from Simple Scalar Variables During Unstable Conditions. Journal of Applied Meteorology 11: 783-792. 
Timmermans, W.J., Gieske, A.S.M., Wolski, P., Arneth, A. and G.N. Parodi. 2003. Determination of water and heat fluxes with MODIS imagery - Maun, Botswana. SPIE Annual Conference, Barcelona, 7-12 Sept. 2003.

Valiente, J. A., Nunez, M., Lopez-Baeza, E. and J.F. Moreno. 1995. Narrow-Band to BroadBand Conversion of Meteosat Visible Channel and Broad-Band Albedo Using Both AVHRR1 and-2 Channels. International Journal of Remote Sensing 16(6): 1147-1166.

Watts, C. J., Chebouni, A., Rodriguez, J. -C., Kerr, Y. H., Hartogensis, O. and H.A.R De Bruin. 2000. Comparison of Sensible Heat Flux Estimates using AVHRR with Scintillometer Measurements over Semi-Arid Grassland in Northwest Mexico. Agricultural and Forest Meteorology 105: 81-89. 